\title{
Modeling of the solubility of Naproxen and Trimethoprim in different solvents at different temperature
}

\author{
Y. Moudjari, W. Louaer, and A-H. Meniai \\ Laboratoire de l'Ingénierie des Procèdes de l'Environnement, Département de Chimie Industrielle, Université Mentouri \\ de Constantine 25100, Algeria
}

\begin{abstract}
The study concerns the prediction of the solubility of pharmaceutical compounds such as Trimethoprim and Naproxen in various solvents like Methanol, Ethanol, 1-Propanol, 2-Propanol, 1-Butanol and 2-Butanol for the first solute and Chloroform, Octanol and Cyclohexane, for the second one. The solubility prediction was performed using thermodynamic models like the UNIFAC, which is a group contribution method, and the semi-predictive model like NRTL. The required interaction parameters for the NRTL are not available and are calculated by optimizing an objective function involving experimental data reported in the literature for the considered systems. Also the obtained results by means of the UNIFAC model for Naproxen showed deviations from the experimental data and therefore new molecular decompositions to generate new groups are proposed and the corresponding interaction parameters are calculated. The influence of the molecular structure on the behavior of the mixture is also discussed. On the other hand a new group representing the Aromatic Nitrogen (AN) present in Trimethoprim is introduced and new interaction parameters concerning these groups are calculated. Finally it may be concluded that the NRTL model led to the best results for the solubility prediction for pharmaceutical compounds.
\end{abstract}

\section{Introduction}

Thermodynamic models are increasingly used by the pharmaceutical industry at different stages of the product and process development and optimization processes. At the product development and formulation stage, various solvents are screened for new pharmaceutical molecules. At the later stage of process development and optimization, appropriate selection of a solvent or a mixture of solvents is critical for the crystallization and other processes. Most of the pharmaceutical molecules are significantly more complex than molecules encountered in oil and chemical industry, with multiple functional polar and hydrogen bonding groups. At the same time, experimental physical property data for most of the pharmaceutical molecules of interest are substantially more limited than data for hydrocarbons and other compounds relevant to oil and gas industries. Generally the solubility of pharmaceutical compounds in various solvents is a key parameter. Its measuring is not always easy and may also be an arduous task when several systems are to be tested. Consequently in this work, the modeling of the solubility of Naproxen (NAP); [2-(6-methoxy-2-naphtyl) propanoic acid] and Trimethoprim (TMP); (2, 4-diamino-5-(3, 4, 5trimethoxy Benzyl) pyrimidine) was carried out using the group contribution method UNIFAC (UNIversal Functional group Activity Coefficients) [1] and the semipredictive model NRTL (Non Random Two Liquid) [2]. The choice of these two compounds i.e. Naproxen and
Trimethoprim was motivated by the fact that experimental solubility values of these two solutes in different organic solvents were reported in the literature [3] and [4], respectively, hence providing an opportunity to assess the reliability of the results obtained from the considered two models.

\section{Thermodynamics}

Similarly to other phase Equilibria, the required thermodynamic relations for solid-liquid can be derived starting from the isofugacity criterion [5]:

$f_{i}^{s}=f_{i}^{l}$

where $s$ refers to solid state and $l$ to the liquid state. The fugacity of the solute in the liquid phase may be expressed as [5]:

$f_{i}^{l}=x_{i}^{l} \gamma_{i}^{l} f_{i}^{\circ} l$

With $f_{i}^{\circ}$ representing the fugacity of the pure solute in a subcooled liquid state below its melting point. When the solvent does not enter the solid phase, the fugacity of the solid solute remains that of pure solid:

$f_{i}^{s}=f_{i}^{\circ} s$

Using Eq. (1), the solubility of the solute $i$ in the liquid phase can be calculated by: 
$x_{i}^{l} \gamma_{i}^{l}=\frac{f_{i}^{o} s}{f_{i}^{o l}}$

An expression for the ratio of the standard fugacities can be obtained via a thermodynamic cycle and after some justified simplifications (Gmehling et al., 1992), as follows:

$\ln \frac{f_{i}^{\circ} s}{f_{i}^{o l}}=\frac{\Delta H_{m}}{\mathrm{R}}\left(\frac{1}{\mathrm{~T}_{m}}-\frac{1}{\mathrm{~T}}\right)$

with the subscript $m$ designating the melting point.

Substituting Eqn. 4 into 5 gives:

$\ln \left(x_{i}^{l} \gamma_{i}^{l}\right)=\frac{\Delta H_{m}}{\mathrm{R}}\left(\frac{1}{\mathrm{~T}_{m}}-\frac{1}{\mathrm{~T}}\right)$

and hence the solubility $x_{i}^{l}$ of a solute in a solvent or solvent mixture which is expressed as:

$x_{i}^{l}=\frac{\exp \left[\frac{\Delta H_{m}}{R}\left(\frac{1}{T_{m}}-\frac{1}{T}\right)\right]}{\gamma_{i}^{l}}$

For the determination of the solubility besides the melting point $\mathrm{T}_{m}$ and the heat of fusion $\Delta H_{m}$ only the activity coefficient of component $i$ is required. While the pure component data can directly be read from the Dortmund Data Bank (DDBST) [6], which presents one of the reliable data bank for pure component and mixture properties. The activity coefficient $\gamma_{i}$ can be calculated. by means of thermodynamic models

\section{Modeling section}

\subsection{The NRTL equation}

The NRTL equation was described in detail for the first time by Renon and Prausnitz (1968) [2] who showed its application to a wide variety of mixtures for the calculation of the fluid phase equilibrium. The model is based on the molecular local composition concept which is expressed as follows:

$x_{j i}=\frac{x_{j} \exp \left(-\alpha_{j i} \tau_{j i}\right)}{\sum_{k=1}^{C} x_{j} \exp \left(-\alpha_{k i} \tau_{k i}\right)}$

For the binary pair $i j, x_{j i}$ is the local mole fraction of a central molecule $i$ surrounded

by molecule $j, \tau_{j i}$ and $\tau_{i j}$ are adjustable parameters, and $\alpha_{j i}\left(=\alpha_{i j}\right)$ are the non-randomness parameter in the mixture and they vary from 0.2 to 0.47 [7].

\subsection{The UNIFAC equation}

UNIFAC is based on the group contribution concept, which assumes that a mixture does not consist of molecules but of functional groups. This reliable and fast technique is described in detail by Fredenslund et al (1977) [1]. According to this model the activity coefficient is expressed as follows:

$\ln \gamma_{i}=\ln \gamma_{i}^{C}+\ln \gamma_{i}^{R}$
The first term $\ln \gamma_{i}^{C}$ concerns the combinatorial part and takes into account the differences in sizes and shapes of the molecules. It can be calculated using van der Waals volumes $\mathrm{R}_{\mathrm{k}}$ and surface areas $\mathrm{Q}_{\mathrm{k}}$ of the functional groups. The second term $\ln \gamma_{i}^{R}$ is the residual part which takes into account the intermolecular forces. The determination of these two contributions requires the knowledge of volume $\left(\mathrm{R}_{\mathrm{k}}\right)$ and surface area $\left(\mathrm{Q}_{\mathrm{k}}\right)$ group parameters as well as binary interaction parameters $\left(a_{m n}\right)$ which may or may not be available in the corresponding tables reported in the literature base [8].

For the considered systems all the group interaction parameters are available except those involving a new group denoted as (AN) and consisting of a nitrogen atom on a benzene ring as shown in Figure 1 for Trimethoprim. Therefore these parameters have to be calculated.

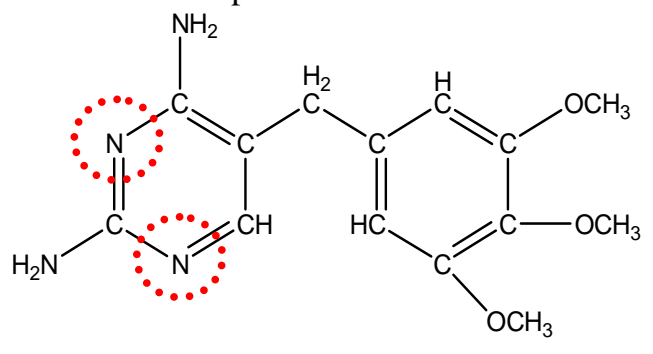

Figure 1. Molecular structure of Trimethoprim [9].

\section{Results and discussion}

Tables 1 and 2 show experimental solubilities of NAP and TMP as reported in the literature [3] and [4], respectively. It is clear from these tables, for both solutes, that the equilibrium solubility increased with temperature. However for NAP the highest solubility value was obtained in pure Chloroform while the lowest one was in Cyclohexane. This can be explained by the fact that Chloroform is a polar organic solvent which may act as a hydrogen donor for establishing hydrogen bonds and hence a lipophilic hydrocarbon solvent, a fact which might explain the much lower solubility of NAP which may have an induced polarity due to its oxygenated heteroatoms by mean of which it could also act as a proton-acceptor compound. For TMP the order of increasing solubility was Methanol> Ethanol > 1Propanol > 1-Butanol > 2-Butanol> 2-Propanol. The results suggested that the polarity of the solvents might be the main factor influencing the solubility. Positive deviations from ideality were exhibited for all systems and thus a much lower solubility than the ideal one.

Table 1. Experimental solubility of NAP in mole fraction in pure solvents.

\begin{tabular}{cccc}
\hline T $(\mathbf{K})$ & $\frac{\text { Octanol }}{\left(\mathbf{X} * \mathbf{1 0}^{\mathbf{2}}\right)}$ & $\frac{\text { Cyclohexane }}{\left(\mathbf{X} * \mathbf{1 0}^{\mathbf{4}}\right)}$ & $\frac{\text { Chloroform }}{\left(\mathbf{X} * \mathbf{1 0}^{\mathbf{2}}\right)}$ \\
\hline $\mathbf{2 9 3 . 1 5}$ & 1.342 & 0.355 & 1.97 \\
$\mathbf{2 9 8 . 1 5}$ & 1.742 & 0.5867 & 2.41 \\
$\mathbf{3 0 3 . 1 5}$ & 2.024 & 0.84 & 2.72 \\
$\mathbf{3 0 8 . 1 5}$ & 2.499 & 1.183 & 3.278 \\
$\mathbf{3 1 3 . 1 5}$ & 2.949 & 1.639 & 3.809 \\
\hline$>\quad \mathrm{T}_{m}=427.6 \mathrm{~K}[10]$ & $; \Delta \mathrm{H}_{m}=31.5 \mathrm{~kJ} /$ mole $[11]$
\end{tabular}


Table 2. Experimental solubility of TMP in mole fraction in pure solvents.

\begin{tabular}{|c|c|c|c|}
\hline $\mathbf{T}(\mathbf{k})$ & $X_{T M P} * 10^{4}$ & $\mathbf{T}(\mathbf{K})$ & $\mathrm{X}_{T M P} * 10^{4}$ \\
\hline \multicolumn{4}{|l|}{ Methanol } \\
\hline 277.02 & 8.282 & 309.36 & 26.49 \\
\hline 282.85 & 10.02 & 314.12 & 32.03 \\
\hline 288.09 & 12.01 & 319.06 & 39.17 \\
\hline 293.03 & 14.32 & 323.53 & 47.1 \\
\hline 298.17 & 17.28 & 328.15 & 57.07 \\
\hline 304.24 & 21.71 & 333.73 & 71.98 \\
\hline \multicolumn{4}{|l|}{ Ethanol } \\
\hline 281.15 & 3.559 & 315.24 & 15.14 \\
\hline 287.25 & 4.605 & 318.85 & 17.72 \\
\hline 292.64 & 5.455 & 323.95 & 22.26 \\
\hline 297.95 & 6.808 & 326.65 & 25.53 \\
\hline 302.05 & 8.332 & 330.66 & 30.85 \\
\hline 307.85 & 10.49 & 335.25 & 38.77 \\
\hline 311.35 & 12.38 & & \\
\hline \multicolumn{4}{|l|}{ 1-Propanol } \\
\hline 277.35 & 2.776 & 308.44 & 10.9 \\
\hline 283.63 & 3.281 & 314.54 & 14.79 \\
\hline 288.97 & 4.141 & 319.17 & 18.65 \\
\hline 294.05 & 5.306 & 323.48 & 23.12 \\
\hline 298.93 & 6.772 & 328.57 & 29.78 \\
\hline 303.84 & 8.66 & 334.15 & 39.15 \\
\hline \multicolumn{4}{|l|}{ 2-Propanol } \\
\hline 277.17 & 1.093 & 309.36 & 6.443 \\
\hline 282.82 & 1.563 & 315.13 & 9.1 \\
\hline 288.28 & 2.023 & 319.53 & 11.7 \\
\hline 293.13 & 2.552 & 324.04 & 15.1 \\
\hline 297.57 & 3.223 & 328.37 & 19 \\
\hline 304.04 & 4.677 & 333.64 & 24.7 \\
\hline \multicolumn{4}{|l|}{ 1-Butanol } \\
\hline 276.35 & 1,57 & 308.84 & 10.6 \\
\hline 282.63 & 2,536 & 313.36 & 13.3 \\
\hline 287.96 & 3,589 & 318.45 & 17.5 \\
\hline 292.84 & 4,727 & 323.73 & 23.5 \\
\hline 298.46 & 6,349 & 329.21 & 30.6 \\
\hline 303.72 & 8,44 & & \\
\hline \multicolumn{4}{|l|}{ 2-Butanol } \\
\hline 276.85 & 1.532 & 308.84 & 10.06 \\
\hline 283.66 & 1.79 & 313.35 & 13.15 \\
\hline 290.08 & 3.002 & 318.46 & 17.23 \\
\hline 294.67 & 4.22 & 323.56 & 23.09 \\
\hline 298.45 & 5.623 & 328.66 & 29.02 \\
\hline 303.74 & 7.581 & 333.74 & 37.73 \\
\hline
\end{tabular}

\section{Estimated interaction parameters}

The binary group interaction parameters involving AN group with other groups, required for the UNIFAC model as well as the molecular interaction parameters for the NRTL model were retrieved in the present work using the Nelder-Mead method [14] for the minimization of the following objective function $\left(\mathrm{F}_{o b j}\right)$ defined as the sum of the squared deviations between the experimental and calculated mole fractions:
$\mathrm{F}_{o b j}=\sum_{i=1}^{N}\left(x_{i(\exp )-} x_{i(c a l)}\right)^{2}$

with $\mathrm{N}$ denoting the number of data points.

Table 3 lists the results of fitting solubility by NRTL and UNIFAC equations for the nine systems presented in this work the best description of solid-liquid equilibrium was given by the NRTL model that delivers the lowest deviation (RMSD). The relative root mean square deviation of solubility is defined as follows:

$\operatorname{RMSD}=\frac{1}{n}\left[\sum_{i=1}^{n}\left(\frac{x_{i(\exp )-x_{i(c a l)}}}{x_{i(\exp )}}\right)^{2}\right]^{1 / 2}$

Where $n$ is the number of experimental points; $x_{i(\text { cal })}$ is the solubility calculated using NRTL and UNIFAC equation; $x_{i(\exp )}$ is the experimental solubility reported in literature.

The obtained results show that the UNIFAC model for Naproxen showed a large deviations. As shown in Figure 2, Naproxen has a methoxyl group $(\mathrm{CH} 3 \mathrm{O})$ which is bonded to an aromatic ring to lead to the proposed group $\mathrm{ACCH} 3 \mathrm{O}$ (aromatic methoxyl). From a structural point of view, it is clear that the behavior of this group would be different from the case of being bonded to an aliphatic chain as reported in the reported UNIFAC tables [8]. Therefore binary interaction parameters involving this group had to be calculated, using the expression given by Eqn. 10 as still the objective function.

The estimated interaction parameters of $\mathrm{ACCH}_{3} \mathrm{O}$ are shown in Table 5 and their use led to solubility results in a quite good agreement with the data reported in the literature, as confirmed by Table 4 giving the relative root mean square deviation for three systems involving NAP.

Table 3. NRTL and UNIFAC modeling results for NAP and TMP.

\begin{tabular}{|c|c|c|}
\hline System & $\begin{array}{c}\text { NRTL } \\
\text { RMSD (\%) }\end{array}$ & $\begin{array}{c}\frac{\text { UNIFAC }}{\operatorname{RMSD}(\%)} \\
\end{array}$ \\
\hline \multicolumn{3}{|l|}{ Naproxen } \\
\hline Octanol & 0.9283 & 33.6369 \\
\hline Cyclohexane & 16.0413 & 40.4328 \\
\hline Chloroform & 0.6568 & 2.432 \\
\hline \multicolumn{3}{|c|}{ Trimethoprim } \\
\hline Methanol & 2.9267 & 10.39 \\
\hline Ethanol & 3.1498 & 29.338 \\
\hline 1-Propanol & 3.494 & 6.4097 \\
\hline 2-Propanol & 3.0242 & 31.64 \\
\hline 1-Butanol & 1.9899 & 2.2616 \\
\hline 2-Butanol & 2.0908 & 3.3052 \\
\hline
\end{tabular}

Table 4. UNIFAC and UNIFAC modeling results for NAP.

\begin{tabular}{l|cc}
\hline Systems & $\frac{\text { UNIFAC }_{\text {stm }}}{\text { RMSD } \%)}$ & $\underline{\text { UNIFAC }}$ \\
& RMSD (\%) \\
\hline NAP/Octanol & 1.2173 & 33.6369 \\
NAP/Cyclohexane & 4.5598 & 40.4328 \\
NAP/Chloroform & 2.432 & 6.6168 \\
\hline
\end{tabular}


Tables 5 and 6 present the obtained binary group and molecular interaction parameters for the UNIFAC and NRTL models, respectively.

Figures 3 and 4 show the predicted results using the NRTL and UNIFAC models together with the experimental and ideal solubility data as function of temperature for the nine considered systems.<smiles>CC(C(=O)O)c1ccc2c(c1)C=CC1=C(C=C2)CCCCC1</smiles>

Figure 2. Molecular structure of NAP [15].
Table 6. Binary interaction parameters for NRTL in $\mathrm{K}\left(\alpha_{i j}=\right.$ $0.3)$.

\begin{tabular}{c|c|c|c}
\hline Solute (1) & Solvent (2) & $\mathrm{a}_{12}$ & $\mathrm{a}_{21}$ \\
\hline \multirow{3}{*}{$\underline{\text { NAP / }}$} & Octanol & -40.0547 & 41.4311 \\
& & & \\
& Cyclohexane & -162.58 & 191.86 \\
& Chloroforme & -62.79 & 65.49 \\
\hline \multirow{5}{*}{$\underline{\text { TMP / }}$} & Méthanol & -87.85 & 92.86 \\
& & & \\
& Ethanol & -63.85 & 67.18 \\
& 1-Propanol & -53.29 & 55.737 \\
& 2-Propanol & -9.41 & 10.51 \\
& 1-Butanol & -42.17 & 43.91 \\
& 2-Butanol & -28.69 & 29.83 \\
\hline
\end{tabular}

Table 5. Binary group interaction parameters $\left(a_{m n}\right)$ in $(\mathrm{K})$ for UNIFAC including $\mathrm{AN}$ and $\mathrm{ACCH}_{3} \mathrm{O}$ groups.

\begin{tabular}{|c|c|c|c|c|c|c|c|c|c|c|}
\hline$a_{m n}$ & AC/ACH & $\mathrm{ACNH}_{2}$ & $\mathrm{ACCH}_{2} / \mathrm{ACCH}$ & $\mathrm{CH}_{3} \mathrm{O}$ & $\overline{A N}$ & $\mathrm{ACCHO}_{3} \mathrm{O}$ & $\mathrm{COOH}$ & $\mathrm{CH}_{3} \mathrm{OH}$ & $\mathrm{CH}_{3} / \mathrm{CH} 2$ & $\overline{\mathrm{OH}}$ \\
\hline AC/ACH & 0 & 648.2 & 167 & 32.14 & 199.19 & 123.22 & 537.4 & 637.35 & -11.12 & 636.1 \\
\hline $\mathrm{ACNH}_{2}$ & 64 & 0 & 762.8 & 285.36 & -97.15 & n.c & 0 & 1139 & -118.1 & -17.4 \\
\hline $\mathrm{ACCH}_{2} / \mathrm{ACCH}$ & -146.8 & 664 & 0 & 213.1 & 53.32 & 175.23 & 872.3 & 603.25 & -69.7 & 803.2 \\
\hline $\mathrm{CH}_{3} \mathrm{O}$ & 52.13 & -46.39 & 65.69 & 0 & 78.86 & n.c & 664.6 & 238.4 & 83.36 & 237.7 \\
\hline $\mathbf{A N}$ & 110.14 & 324.62 & -104.99 & 39.798 & 0 & n.c & n.c & -520 & -149.5 & -410.4 \\
\hline $\mathrm{ACCH}_{3} \mathrm{O}$ & 98.745 & n.c & 238.05 & n.c & n.c & 0 & 508.275 & n.c & 561.285 & 494.025 \\
\hline $\mathrm{COOH}$ & 62.32 & 0 & 89.86 & -338.5 & n.c & -208.15 & 0 & 1020 & 315.3 & -151 \\
\hline $\mathrm{CH}_{3} \mathrm{OH}$ & -50 & 489.7 & -44.5 & -128.6 & -40 & n.c & -289.5 & 0 & 16.51 & 249.1 \\
\hline $\mathrm{CH}_{3} / \mathrm{CH} 2$ & 61.13 & 920.7 & 76.5 & 251.5 & 318.5 & 645.294 & 663.5 & 697.2 & 0 & 986.5 \\
\hline OH & 89.6 & -52.39 & 25.82 & 28.06 & -25.86 & 122.31 & 199 & -137.1 & 156.4 & 0 \\
\hline
\end{tabular}

(a)

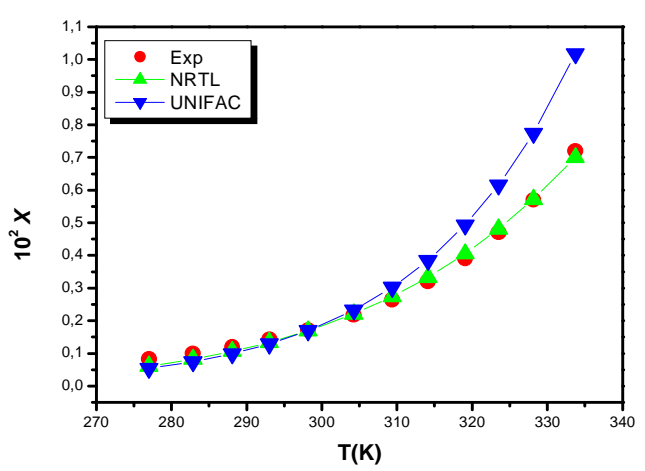

(b)

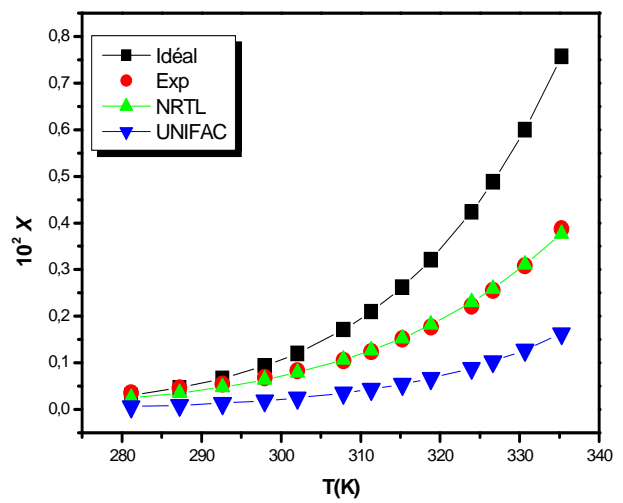


(c)

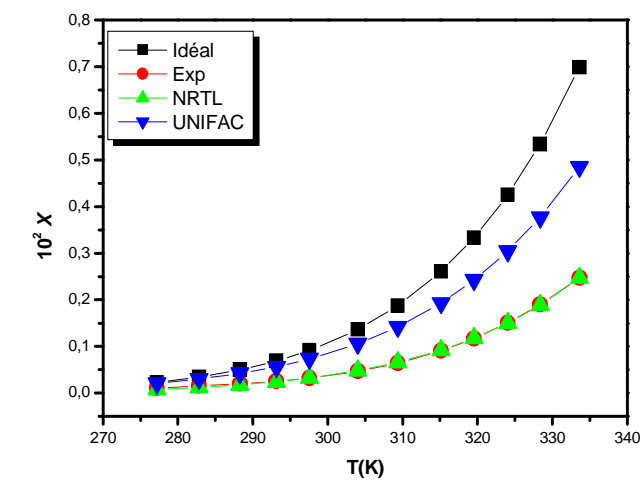

(e)

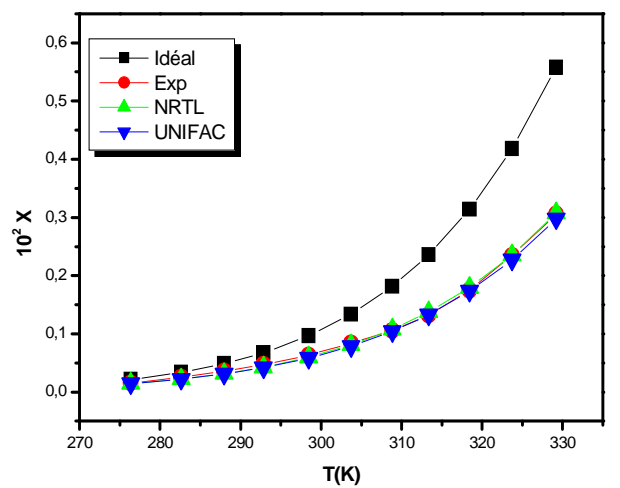

(d)

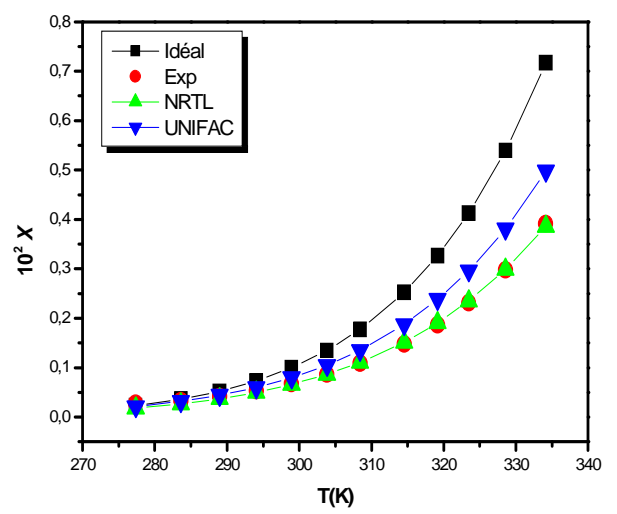

(f)

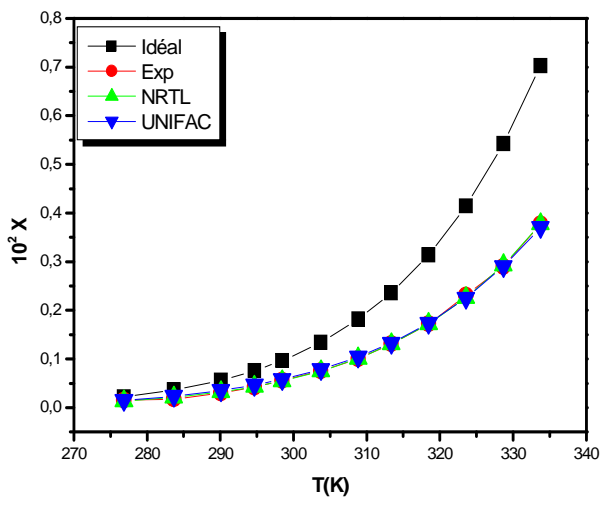

Figure 3. Mole fraction solubility of TMP in various solvents: (a) methanol; (b) ethanol; (c) 2-propanol; (d) 1-propanol; (e) 1-butanol; (f) 2-butanol.

(a)

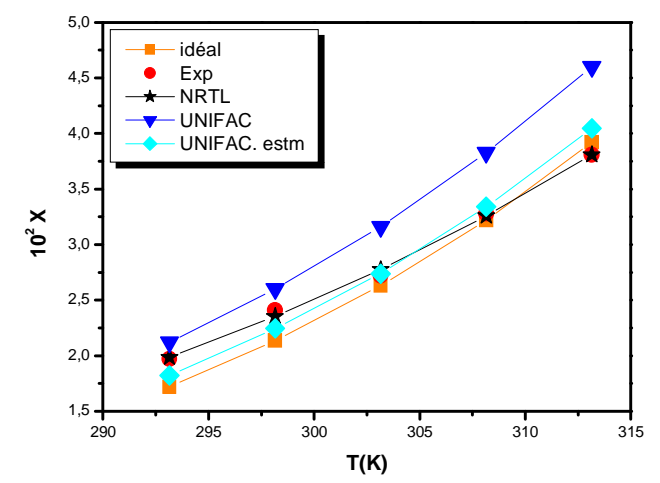

(b)

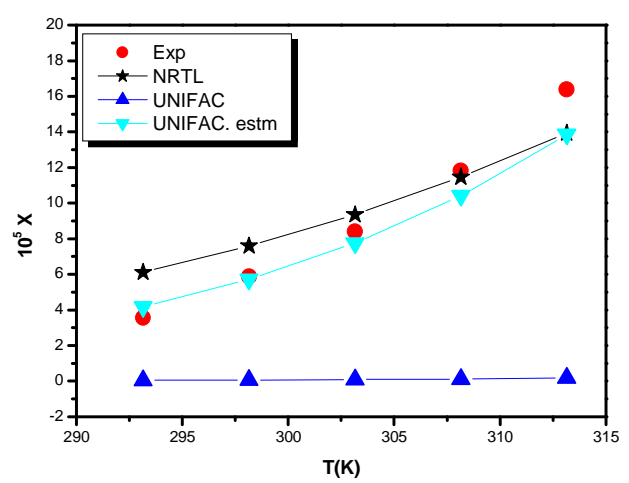


(c)

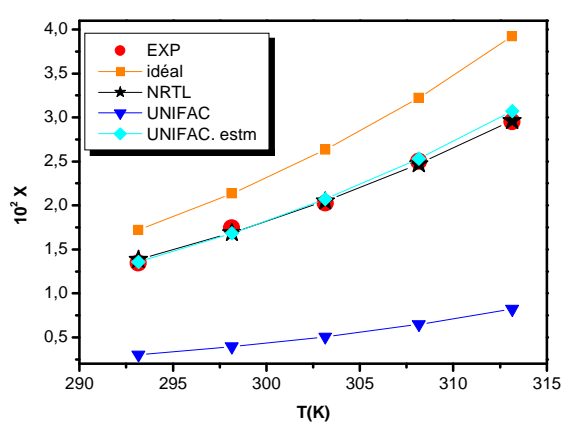

Figure 4. Mole fraction solubility of NAP in various solvents; (a) Octanol; (b) Chloroform; (c) Cyclohexane.

\section{Conclusion}

The present study has clearly demonstrated the importance of modeling solid-liquid phase equilibria, particularly for sensitive industrial fields like pharmaceuticals. However, the influence of the molecular structure decomposition into groups, on the accuracy of activity models like the UNIFAC has also been showed. Globally the models using molecular interaction parameters led to more accurate results compared to models using group interaction parameters like the UNIFAC. This is perhaps due to the fact that any group contribution approach is assumed approximately to be additive.

\section{Appendix: Calculation of (RK) and (QK) of "AN" and "ACCH3O" groups}

$\mathrm{R}_{(\mathrm{AN})}=\frac{\mathrm{V} w(\mathrm{AN})}{15.17}$

$\mathrm{V}_{w(\mathrm{AN})}=5.19876$ (Bondi 1968.)

$\mathrm{R}_{(\mathrm{AN})}=0.3427$

$\mathrm{Q}$ (AN) were obtained by means of the following simple relationships [16]:

$\mathrm{Q}_{(\mathrm{AN})}=\frac{(z-2) \mathrm{R}_{\mathrm{AN}}}{Z}+\frac{2(1-l i)}{Z}$

$\mathrm{Q}_{(\mathrm{AN})}=0.2742$

$z$ the coordination number, assumed to be equal to 10 and $l_{i}$ is the bulk factor; it was assumed that $l_{i}=1$ for cyclic molecules[16]

$\mathrm{R}_{(\mathrm{ACCH} 3 \mathrm{O})}=\mathrm{R}_{(\mathrm{AC})}+\mathrm{R}_{(\mathrm{CH} 3 \mathrm{O})}$

$\mathrm{R}_{(\mathrm{ACCH} 3 \mathrm{O})}=1.5012$

$\mathrm{Q}_{(\mathrm{ACCH} 3 \mathrm{O})}=\mathrm{Q}_{(\mathrm{AC})}+\mathrm{Q}_{(\mathrm{CH} 3 \mathrm{O})}$

$\mathrm{Q}_{(\mathrm{ACCH} 3 \mathrm{O})}=1.208$

\section{References}

1. R.C. Reid, B.E. Poling, J.M. Prausnitz, The Properties of Gases and Liquids, $4^{\text {th }}$ ed., McGrawHill, New York, 1987
2. H. Renon, J.M. Prausnitz, ALChEJ 14135 (1975)

3. C.P. Mora, F. Martinez, Fluid Phase Equilib. 25570 (2007)

4. A. Jouyban, Handbook of solubility data of pharmaceutical, CRC Press, USA, 2010

5. I. Hahnenkamp, J. Gmehling, Inter Journal of pharmaceutics 38873 (2010)

6. Dortmund Data Bank (DDBST), Oldenburg, 2008 http:// www.ddbst.de

7. D. Wei, L. Chen, Fluid Phase Equilib. 2779 (2009)

8. http://www.aim.env.uea.ac.uk/aim/ info/UNIFACgroups.html

9. N. Li, Y.-H. Zhang, J.Pharm and Biomedical Analysis 38370 (2005)

10. G.L. Perlovich, S.V. Kurkov, Eur. J. Pharm. Biopharm. 57411 (2004)

11. D.P. Pacheco, F. Martinez, Fluid Phase Equilib. 2779 (2009)

12. N. Li, Y.-H. Zhang, J.Pharm and Biomedical Analysis 39824 (2005)

13.P.G. Rao, K.R. Prakash, Pharmaceutica Acta Helvetiae 71175 (1991)

14. J.A. Nelder and R. Mead, Comput. J. 7308 (1965)

15. G.A. Rodriguez, D.R. Delgado, Fluid Phase Equilib. 32049 (2012)

16. U. Domanska, A. Pobudkowska, Fluid Phase Equilib. 206341 (2003) 